\title{
Opioid Induced Constipation
}

\author{
Caterina Aurilio, Maria Caterina Pace, Vincenzo Pota and Pasquale Sansone \\ Department of Anesthesiological, Surgical and Emergency Science, \\ Second University of Naples, Naples, \\ Italy
}

\section{Introduction}

The prevalence of chronic pain in the adult population ranges from 2 to 40 (1-3). The chronic use of opioids for the treatment of non-cancer pain is commonly encountered in clinical practice.

The American Society of the Interventional Pain Physicians has issued guidelines for appropriate use of opioids (4).

With the increased use of opioids, there are more patients presenting with opioid induced constipation (OIC) or opioid bowel dysfunction (OBD) $(5,6)$.

The definitions of constipation include a reference to infrequent, difficult or incomplete bowel evacuation that may lead to pain and discomfort; with stools that can range from small, hard 'rocks', to a large bulky mass. Constipation may be debilitating among those who require chronic analgesia (7); OIC or OBD affected an average of $41 \%$ patients taking an oral opioid for up to 8 weeks in a meta-analysis of 11 placebo-controlled, randomized studies in non-malignant pain (14). In a survey of patients taking opioid therapy for pain of non-cancer origin, who required laxative therapy, only $46 \%$ of opioid-treated patients reported achieving the desired treatment results $>50 \%$ of the time, in contrast to the reported satisfaction in $84 \%$ of control subjects (8).

The prevalence of constipation was $46.9 \%$ and chronic abdominal pain $58.2 \%$ among 100 ambulatory patients with moderate-to-severe chronic non-cancer pain.

In the United States and European survey of 322 patients taking daily oral opioids and laxatives, $45 \%$ of patients reported < 3 bowel movements per week, $81 \%$ reported constipation, and $58 \%$ straining, symptoms were most oft en reported as severe, had at least a moderate negative impact on overall quality of life and activities of daily living. The objectives of this narrative review are to summarize essential aspects of the epidemiology of opiateinduced constipation (OIC), summarize the effects of opiates on gastrointestinal functions that lead to constipation, evaluate pharmacological approaches to treat or prevent OIC.

\section{Pathophysiology of opioid induced constipation}

The opioid receptors identified as having effects on human gastrointestinal function are $\delta$-, $\kappa-$, and $\mu$-receptors. They all belong to the family of G-protein-coupled receptors, and 
inhibit adenylate cyclase. The m-receptors are the principal mediators of the analgesic action of endogenous and exogenous opioids as well as of the major side-effects, ie, sedation, bowel dysfunction, respiratory depression, and dependence. At the membrane level, they reduce neuronal excitability and neurotransmitter (acetylcholine) release (9) with an overall inhibitory effect on the neuron.

Opioid receptors are widely distributed in the central and peripheral nervous system, the intestinal musculature, and other tissues. In the gastrointestinal tract, $\mu$-receptors are widely distributed in the submucosa (10), as well as in the ileal mucosa. They influence ion transport changes (11). While $\mu-$ and $\mathrm{\kappa}$-opiate receptors are more representative in stomach and proximal colon (12).

The cause of constipation in opiate users is multi-factorial (13). Opioids interfere with normal gastrointestinal motility by delaying transit, stimulating non-propulsive motility, segmentation and tone, and stimulation of sphincters such as the pylorus and ileocecal sphincter (13) through their effects on enteric neurons (14). They can also stimulate the absorption of fluids, mainly by delayed transit, and by stimulating mucosal sensory receptors that activate a reflex arc that facilitates further fluid absorption $(15,16)$. These multiple effects lead to OIC.

\section{Pharmacological approach to OIC}

\section{$3.1 \mu$-opioid receptor agonists}

\section{Tapentadol}

Tapentadol HCI is a $\mu$-opioid agonist that also inhibits norepinephrine reuptake (17). The analgesic effect is so a combination of two different mechanism. In different trials norepinephrine reuptake inhibition (e.g., with venlafaxine (18) and the a 2-adrenergic agonist clonidine $(19,20)$ are associated with reduced colonic or rectal sensation in response to distension. Moreover it seems that, because of the combined analgesic action of tapentadol, the pain control can be achieved with a relatively lower level of $\mu$-opioid agonism, which therefore reduces the gastrointestinal adverse effects such as constipation. As an analgesic tapentadol has a more favorable gastrointestinal side-effect profile than the classic $\mu$-opioid receptor agonist oxycodone (21).

However, there were substantially lower incidences of gastrointestinal-related adverse effects with tapentadol extended release than with oxycodone controlled release (22). Similarly, tapentadol extended release, 100- 250 mg b.i.d., effectively relieved moderate-tosevere chronic low back pain over 15 weeks with a better gastrointestinal tolerability than oxycodone $\mathrm{HCl}$ controlled release, 20 - $50 \mathrm{mg}$ b.i.d. (23). Studies of the pharmacodynamic effects of tapentadol on gastric emptying and colonic transit would be of significant interest.

\section{$3.2 \mu$-opioid receptor antagonists}

The main problem in using opioid antagonist for reversing the gastrointestinal adverse effects of opioid that the dose efficaciousness in reversing OIC may inhibit the analgesic effect of opioids, causing either opiate withdrawal symptoms or reversal of desirable analgesia. 


\section{Naloxone}

Naloxone is a competitive antagonist at opioid receptors with much greater affinity for $\mu$ than for $\mathrm{K}$ - or $\delta$-receptors. Naloxone blocks opioid intestinal receptors and has low systemic bioavailability $(2 \%)$ due to a marked hepatic first-pass effect. In patients with chronic pain, oral naloxone improved symptoms of laxation (24), but because of its very narrow therapeutic index, doses that reverse gut symptoms can often cause reversal of analgesia (25). However, there has been a resurgence of interest in naloxone in a prolonged-release preparation, which shows evidence of analgesic efficacy and safety when used in combination with oxycodone (prolonged release) for moderate-to-severe chronic pain (26) and improved bowel function when compared with oral oxycodone (prolonged release) alone (27). This effiacy continues for up to 52 weeks in patients with non-cancer chronic pain (28).

\section{Naltrexone extended release}

There one open-label study that evaluated the safety of a combination of extended-release pellets of morphine sulfate with a sequestered naltrexone core (administered once or twice daily) in patients with chronic, moderate to-severe pain. The pain-relieving objectives of treatment were achieved using dosages of the combination that could be adjusted in accordance with the investigator' $\mathrm{s}$ best medical judgment. The median average daily dose of morphine over the course of study in the safety population was $58.6 \mathrm{mg}$. 465 patients received one or more doses, 160 completed the 12-month study: $30 \%$ of the discontinuations occurred in the first month, most often because of adverse events (23.7 \%), nausea (5.4\%), constipation in $(3.4 \%)$, and vomiting in (2.6\%). Most of the 465 patients (81.3\%) experienced one or more adverse events, most commonly constipation $(31.8 \%)$ or nausea $(25.2 \%)$. Opiate withdrawal symptoms were mild and affected $<5 \%$ of patients during each week of the study (29). Form these data the authors concluded that combination does not resolve OBD.

\subsection{Association of opioid agonist and antagonist}

\section{Oxycodone/Naloxone}

A new oral formulation (oxycodone/naloxone, $\mathrm{OXN}$ ) that combines prolonged-release oxycodone (PRO) and prolonged-release naloxone (PRN) was devel- oped. The ratio of 2:1 PRO to PRN was chosen for the new tablets, which have different strengths: $5 / 2.5 \mathrm{mg}, 10 / 5$ $\mathrm{mg}, 20 / 10 \mathrm{mg}$ and $40 / 20 \mathrm{mg}[30,31]$. The aim of this formulation is to counteract opioidinduced con- stipation (OIC) development [32] through naloxone local antagonist effect on the opioid receptors in the gut wall [33] while maintain analgesia [35] due to the high systemic oxycodone availability after oral ad- ministration (60-87\%)

Meissner et al. [30] reported a randomized, double- blind study that assessed analgesic efficacy and, impact on the OIC of OXN and identified the optimal dose ratio of oxycodone and naloxone. Two hundred and two patients with chronic pain (most non-malignant, $2.5 \%$ cancerrelated pain) and stable oxycodone dose (40,60 or $80 \mathrm{mg}$ per day) were randomized into groups that received 10,20, and $40 \mathrm{mg}$ per day naloxone or placebo. After 4 weeks of the maintenance phase, patients received oxycodone for two weeks. Pain intensity was evaluated by the NRS, and bowel function was assessed by the bowel function index (BFI). No loss of analgesia with naloxone was observed. Na- loxone at doses of 20 and $40 \mathrm{mg}$ improved bowel 
function in comparison to placebo $(p<0.05)$. The combination was well tolerated with no unexpected adverse effects. A trend towards an increase in diarrhea with the higher naloxone doses was observed. The 2:1 oxyco- done/naloxone ratio was identified as the most suitable.

\subsection{Peripherally restricted $\mu$ - opiate receptor antagonists}

\section{Methylnaltrexone}

Methylnaltrexone is a quaternary ammonium derivative of naltrexone, an opioid antagonist similar to naloxone, but it is less lipid soluble, so, less likely to cross the blood-brain barrier (36). Methylnaltrexone blocks acute morphine-induced delay in orocecal transit time without affecting analgesia or causing central opiate withdrawal symptoms.

Intravenous methylnaltrexone infusion reversed methadone induced constipation, increasing stool frequency and decreasing orocecal transit times $(37,38)$. Orally administered methylnaltrexone showed the same results (39) with plasma drug levels were very low, suggesting a local site of action in the gut.

Several studies evaluated the effect of methylnaltrexone on apin and OIC. Methylnaltrexone, $0.45 \mathrm{mg} / \mathrm{kg}$ intravenously (i.v.), reversed the effects of 0.05 and 0.1 $\mathrm{mg} / \mathrm{kg}$ morphine on orocecal transit in healthy volunteers (40)

Methylnaltrexone (at a dose of $0.15 \mathrm{mg} / \mathrm{kg}$ subcutaneously (s.c.), every other day for 2 weeks) was tested for OIC in advanced illness in 133 patients who had received opioids for 2 or more weeks and had received stable doses of opioids and laxatives for 3 or more days without relief of OIC (41). Methylnaltrexone s.c. has been approved by the US Food and Drug Administration, Health Canada and the European Medicines Agency (42). The approved indication is OIC in patients with advanced illness receiving palliative care after failing laxative therapy, and the usual dosing schedule is 1 dose every other day, as needed, but no more frequently than 1 dose in a $24-\mathrm{h}$ period. The recommended dose of methylnaltrexone is 8 $\mathrm{mg}$ for patients weighing 38- $62 \mathrm{~kg}$ or $12 \mathrm{mg}$ for patients weighing $62-114 \mathrm{~kg}$. Patients whose weight falls outside of these ranges should be dosed at $0.15 \mathrm{mg} / \mathrm{kg}(43)$.

\section{Alvimopan}

Alvimopan is an orally administered, peripherally acting $\mu$-opioid receptor antagonist that does not cross the blood - brain barrier at clinically relevant dosages (44) and does not reverse analgesia or cause opioid withdrawal symptoms. At the moment, Alvimopan is not approved for treatment of OIC. However, there is already significant literature about its potential in OIC associated with chronic opioid therapy.

In a study of 522 subjects reporting $<3$ spontaneous bowel movements (SBMs) per week and a pain treatment with $\geq 30 \mathrm{mg}$ oral morphine equivalent unit / day, were evaluated the efficacy of alvimapan on OIC. (45) Participants were randomized to receive alvimopan, 0.5 $\mathrm{mg}$ b.i.d., $1 \mathrm{mg}$ once daily, $1 \mathrm{mg}$ b.i.d., or placebo for 6 weeks (45). There was a significant increase in mean SBM / week over the initial 3 weeks of treatment with all 3 doses of alvimopan tested, as well as improvements in straining, stool consistency, incomplete evacuation, abdominal bloating/discomfort, and decreased appetite, which were sustained over 6 weeks. The most frequent adverse events were abdominal pain, nausea, and diarrhea, occurring more frequently in the higher dosage groups. The alvimopan $0.5 \mathrm{mg}$ b.i.d. dose 
demonstrated the best benefit-to-risk profile for managing OBD, with a side-effect profile similar to that of placebo (45). There was no evidence of opioid analgesia antagonism.

\section{NKTR-118}

NKTR-118 is an oral PEGylated naloxol conjugate that blocks peripheral $\mu$-opioid receptors in the gut. PEGylation of naloxone alters its distribution, reducing central nervous system penetration and metabolism (reduced first-pass effect) while retaining its opioid antagonist properties peripherally (46).

In human pharmacodynamic studies, NKTR-118 normalized morphine-induced delay in orocecal transit (47), while central effects were maintained with uninhibited pupillary constriction.

In a phase 2, placebo-controlled clinical trial of NKTR-118 in OIC patients ( < 3 SBM/ week, on a stable opioid dose of 30-1,000 morphine-equivalent unit / day for $\geq 2$ weeks), 208 patients were randomized into three sequential cohorts of 5, 25, or $50 \mathrm{mg}$ for 4 consecutive weeks aft er a 1-week placebo run-in phase. Patients receiving $25 \mathrm{mg}$ or $50 \mathrm{mg}$ (but not 5 mg) NKTR-118 had significantly increased (over baseline) number of SBM during the first week of treatment (primary end point) and over the 28-day treatment period, compared with placebo. There was no evidence of opioid withdrawal, reversal of analgesia, or increase in opioid use at any dose tested. Most frequent side eff ects were abdominal cramping, diarrhea, nausea, and vomiting, which were more frequent in the $50 \mathrm{mg}$ cohort. TD-1211 TD-1211 is an orally administered, peripherally selective, multivalent inhibitor of the $\mu$ opioid receptor. It has high affinity for human $\mu$ - and $\delta$-receptors, and guinea-pig $\mu$-opioid receptors, with $>6,000$-fold selectivity for the $\mu$-opioid receptor over non-opioid receptors, ligand-gated ion channels, enzymes, ion channels (including hERG), and transporters. It inhibits loperamide-induced reduction in gastric emptying and attenuation of castor oilinduced diarrhea following acute oral dosing to conscious rats.

\subsection{Prucalopride, a prokinetic 5-HT 4 receptor agonist}

Prucalopride is a new, selective 5-HT 4 agonist with efficacy in relief of chronic constipation and safety from a cardiovascular perspective. In a phase 2, double-blind, placebo-controlled study 196 patients with OIC were randomized to receive placebo, prucalopride 2 or $4 \mathrm{mg}$ for 4 weeks. The increase from baseline of $\geq 1$ spontaneous complete bowel movements (SCBM) per week (weeks $1-4$, primary end point) was greater in the prucalopride groups ( $35.9 \%$ (2 $\mathrm{mg})$ and $40.3 \%(4 \mathrm{mg})$ than placebo $(23.4 \%)$, reaching statistical significance in week 1 . Prucalopride, $4 \mathrm{mg}$, significantly improved patient-rated severity of constipation and effectiveness of treatment vs. placebo, and improved Patient Assessment of Constipation Symptom (PAC-SYM) total scores and Patient Assessment of Constipation-Quality of Life (PAC-QOL) total and satisfaction subscale scores. The most common adverse events were abdominal pain and nausea.

\section{Lubiprostone}

Lubiprostone is a chloride channel activator that induces intestinal secretion.

Lubiprostone, in vitro, stimulates chloride secretion that was suppressed by morphine. In vivo, instead, s.c. lubiprostone increased fecal wet weight and numbers of pellets expelled in guinea-pig and mouse (48) reduced by Morphine. 
Injection of lubiprostone, $30 \mathrm{~min}$ after morphine, reversed morphine-induced suppression of fecal wet weight. The data suggest that lubiprostone, bypasses the neurogenic constipating effects of morphine by directly opening chloride channels in the mucosal epithelium (48).

\section{Conclusion}

The management of patients with OIC is an increasingly relevant problem with the extensive use of opioids for the relief of chronic pain, often associated with benign conditions. Several novel pharmacological approaches are being developed, including assessment of promotility and secreta- gogue agents that have efficacy in chronic idiopathic constipation. Other approaches are directed at the reversal of peripheral opiate effects in the gut while maintaining the desired analgesic efficacy. Several new approaches are promising, including tapentadol, combination of opioids with prolonged release naloxone, NKTR-118, and TD-1211. An evidence-based management approach for OIC will be more feasible after the new generation of drugs is formally and thoroughly studied in large, high-quality clinical trials.

\section{References}

[1] Verhaak PF, Kerssens JJ, Dekker J et al. Prevalence of chronic benign pain disorder among adults: A review of the literature. Pain 1998; $77: 231-9$.

[2] Blyth FM, March LM, Brnabic AJ et al. Chronic pain in Australia: a prevalence study. Pain 2001; $89: 127-34$.

[3] Breivik H, Collett B, Ventafridda V et al. Survey of chronic pain in Europe: prevalence, impact on daily life, and treatment. Eur J Pain 2006; $10: 287-333$.

[4] Trescot AM, Helm S, Hansen $\mathrm{H}$ et al. Opioids in the management of chronic non-cancer pain: an update of American Society of the Interventional Pain Physicians' (ASIPP) Guidelines. Pain Physician 2008; 11 (2 Suppl) : S5 - S62.

[5] Kalso E, Edwards JE, Moore A et al. Opioids in chronic non-cancer pain:systematic review of effi cacy and safety. Pain 2004; 112 : $372-80$.

[6] Papagallo M. Incidence, prevalence and management of opioid bowel dysfunction. Am J Surg 2001; 182 (November Suppl) : S11 - 8.

[7] Benyamin R, Trescot AM, Datta S et al. Opioid complications and side effects. Pain Physician 2008; 11 (2 Suppl) : S105 - 20.

[8] Pappagallo M. Incidence, prevalence, and management of opioid bowel dysfunction. Am J Surg 2001; 182 (5A Suppl) : $11 S$ - 8S.

[9] Rang HP, Dale MM, Ritter JM. Analgesic drugs. Pharmacology 1999; $13: 579$ - 603.

[10] Kurz A, Sessler DI. Opioid-induced bowel dysfunction: pathophysiology and potential new therapies. Drugs 2003; $63: 649-71$.

[11] Stefano GB, Goumon Y, Casares F et al. Endogenous morphine. Trends Neurosci 2000; $23: 436-42$.

[12] Bagnol D, Mansour A, Akil H et al. Cellular localization and distribution of the cloned mu and kappa opioid receptors in rat gastrointestinal tract. Neuroscience 1997; 81 : $579-91$.

[13] McKay JS, Linaker BD, Turnberg LA. Infl uence of opiates on ion transport across rabbit ileal mucosa. Gastroenterology 1981; $80: 279$ - 84 .

[14] Fickel J, Bagnol D, Watson SJ et al. Opioid receptor expression in the rat gastrointestinal tract: a quantitative study with comparison to the brain. Brain Res Mol Brain Res 1997; 46 : 1 - 8 . 
[15] De Schepper HU, Cremonini F, Park MI et al. Opioids and the gut: pharmacology and current clinical experience. Neurogastroenterol Motil 2004; $16: 383$ - 94.

[16] Wood JD, Galligan JJ. Function of opioids in the enteric nervous system. Neurogastroenterol Motil 2004; 16 (Suppl 2) : 17 - 28.

[17] Kress HG. Tapentadol and its two mechanisms of action: is there a new pharmacological class of centrally-acting analgesics on the horizon? Eur J Pain 2010; 14 : 781 - 3.

[18] Chial HJ, Camilleri M, Ferber I et al. Eff ects of venlafaxine, buspirone, and placebo on colonic sensorimotor functions in healthy humans. Clin Gastroenterol Hepatol $2003 ; 1: 211-8$.

[19] Viramontes BE, Malcolm A, Camilleri M et al. Eff ects of an alpha(2)-adrenergic agonist on gastrointestinal transit, colonic motility, and sensation in humans. Am J Physiol Gastroint Liver Physiol 2001; 281 : G1468 - 76.

[20] Camilleri M, Busciglio I, Carlson P et al. Pharmacogenetics of low dose clonidine in irritable bowel syndrome. Neurogastroenterol Motil 2009; $21: 399-410$.

[21] Candiotti KA, Gitlin MC. Review of the eff ect of opioid-related side eff ects on the undertreatment of moderate to severe chronic noncancer pain: tapentadol, a step toward a solution? Curr Med Res Opin 2010; $26: 1677$ - 84.

[22] Afilalo M, Etropolski MS, Kuperwasser B et al. Effi cacy and safety of tapentadol extended release compared with oxycodone controlled release for the management of moderate to severe chronic pain related to osteoarthritis of the knee: results of a randomized, double-blind, placebo- and activecontrolled phase 3 study. Clinical Drug Invest 2010; 30 : 489 - 505.

[23] Buynak R, Shapiro DY, Okamoto A et al. Efficacy and safety of tapentadol extended release for the management of chronic low back pain: results of a prospective, randomized, double-blind, placebo- and active-controlled phase III study. Expert Opin Pharmacother 2010; 11 : 1787 - 804.

[24] Meissner W, Schmidt U, Hartmann M e t al. Oral naloxone reverses opioid associated constipation. Pain 2000; $84: 105-9$.

[25] Sykes NP. An investigation of the ability of oral naloxone to correct opioid-related constipation in patients with advanced cancer. Palliat Med 1996; $10: 135-44$.

[26] Vondrackova D, Leyendecker P, Meissner W et al. Analgesic efficacy and safety of oxycodone in combination with naloxone as prolonged release tablets in patients with moderate to severe chronic pain. J Pain 2008; $9: 1144-54$.

[27] Meissner W, Leyendecker P, Mueller-Lissner S et al. A randomised controlled trial with prolonged-release oral oxycodone and naloxone to prevent and reverse opioid-induced constipation. Eur J Pain 2009; $13: 56$ - 64.

[28] Sandner-Kiesling A, Leyendecker P, Hopp M et al. Long-term efficacy and safety of combined prolonged-release oxycodone and naloxone in the management of noncancer chronic pain. Int J Clin Pract 2010; 64 : 763 - 74.

[29] Webster LR, Brewer R, Wang $C$ et al. Long-term safety and effi cacy of morphine sulfate and naltrexone hydrochloride extended release capsules, a novel formulation containing morphine and sequestered naltrexone, in patients with chronic, moderate to severe pain. J Pain Symptom Manage 2010; $40: 734-46$

[30] Foss JF. A review of the potential role of methyl-naltrexone in opioid bowel dysfunction. Am J Surg 2001; 182 (5A Suppl) : 19S - 26S.

[31] Meissner W, Leyendecker P, Meuller-Lissner S, Nad- stawek J, Hopp M, Ruckes C, Wirz $S$ et al.: A random- ised controlled trial with prolonged-release oral oxyco- 
done and naloxone to prevent and reverse opioid-induced constipation. Eur J Pain, $2009,13,56-64$.

[32] Müller-Lissner S, Leyendecker P, Hopp M, Ruckes C, Fleischer W, Reimer K: Oral prolonged release (PR) oxycodone/naloxone combination reduces opioid- induced bowel dysfunction (OIBD) in patients with se- vere chronic pain. Eur J Pain, 2007, 11 , abstract 189

[33] De Shepper HU, Cremonini F, Park MI, Camilleri M: Opioids and the gut: pharmacology and current clinical experience. Neurogastroenterol Motil, 2004, 16, 383-394.

[34] Liu M, Wittbrodt E: Low-dose oral naloxone reverses opioid-induced constipation and analgesia. J Pain Symp- tom Manage, 2002, 23, 48-53.

[35] Davis MP, Varga J, Dickerson D, Walsh D, LeGrand SB, Lagman R: Normal-release and controlled-release oxy- codone: pharmacokinetics, pharmacodynamics, and con- troversy. Support Care Cancer, 2003, 11, 84-92.

[36] Yuan CS. Methylnaltrexone mechanisms of action and eff ects on opioid bowel dysfunction and other opioid adverse eff ects. Ann Pharmacother 2007; 41 : 984 - 93.

[37] Yuan CS, Foss JF, O ' Connor $\mathrm{M}$ et al. Methylnaltrexone for reversal of constipation due to chronic methadone use: a randomized controlled trial. JAMA 2000; $283: 367-72$.

[38] Yuan CS, Foss JF, Osinski J et al. Th e safety and effi cacy of oral methylnaltrexone in preventing morphine-induced delay in oral-cecal transit time. Clin Pharmacol Th er 1997; $61: 467-75$.

[39] Yuan CS, Foss JF, O' Connor M et al. Methylnaltrexone prevents morphine- induced delay in oral-cecal transit time without aff ecting analgesia: a double-blind randomized placebo-controlled trial. Clin Pharmacol Ther 1996; 59 : 469 - 75.

[40] Thomas J, Karver S, Cooney GA et al. Methylnaltrexone for opioid-induced constipation in advanced illness. N Engl J Med 2008; 358 : 2332 - 43.

[41] Lang L. Th e food and drug administration approves methylnaltrexone bromide for opioid-induced constipation. Gastroenterology 2008; $135: 6$.

[42] http://www.thomsonhc.com/hcs/librarian/MICROMEDEX: Physician's Desk Reference: methylnaltrexone.

[43] Schmidt WK. Alvimopan (ADL 8-298) is a novel peripheral opioid antagonist. Am J Surg 2001; $182: 27$ - 38S.

[44] Webster L, Jansen JP, Peppin J et al. Alvimopan, a peripherally acting mu-opioid receptor (PAM-OR) antagonist for the treatment of opioid induced bowel dysfunction: results from a randomized, double-blind, placebo-controlled, dose-fi nding study in subjects taking opioids for chronic non-cancer pain. Pain 2008; 137 : 428 - 40.

[45] Eldon MA, Song D, Neumann TA et al. Oral NKTR-118 (oral PEGnaloxol), a PEGylated derivative of naloxone; demonstration of selective peripheral opioid antagonism aft er oral administration in preclinical models. American Academy of Pain Management 18th Annual Clinical Mtg., Las Vegas, NV, 27 - 30 September 2007, poster 28.

[46] Neumann TA, van Paaschen H, Marcantonio A et al. Clinical investigation of oral NKTR-118 as a selective oral peripheral opioid antagonist. $18^{\text {th }}$ Annual Clinical Mtg. of the American Academy of Pain Management, Las Vegas, NV, Sept. 27-30, 2007, abstract 27.

[47] Fei G, Raehal K, Liu S et al. Lubiprostone reverses the inhibitory action of morphine on intestinal secretion in guinea pig and mouse. J Pharmacol Exp Th er 2010; 334 : 333 -40 . 


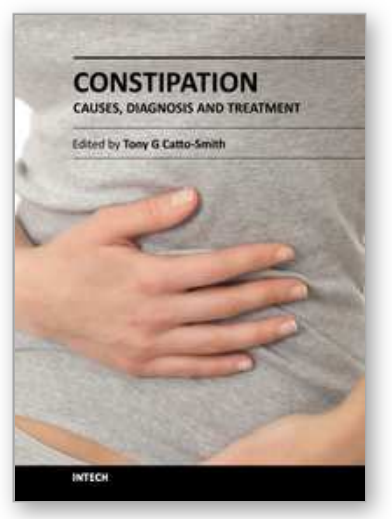

\author{
Constipation - Causes, Diagnosis and Treatment \\ Edited by Dr. Anthony Catto-Smith
}

ISBN 978-953-51-0237-3

Hard cover, 172 pages

Publisher InTech

Published online 07, March, 2012

Published in print edition March, 2012

Constipation is common in both adults and children. Estimates would suggest a median prevalence of around $12-16 \%$ in the general population. While regarded as a minor nuisance in some cases, its consequences can be severe, with a substantial impact on quality of life. Secondary faecal soiling has a profound psychological effect at all ages. This book provides contributions from authors with a range of backgrounds which clarify the pathogenesis, diagnosis, and therapy of constipation for the general population and also for certain high risk groups.

\title{
How to reference
}

In order to correctly reference this scholarly work, feel free to copy and paste the following:

Caterina Aurilio, Maria Caterina Pace, Vincenzo Pota and Pasquale Sansone (2012). Opioid Induced Constipation, Constipation - Causes, Diagnosis and Treatment, Dr. Anthony Catto-Smith (Ed.), ISBN: 978-95351-0237-3, InTech, Available from: http://www.intechopen.com/books/constipation-causes-diagnosis-andtreatment/etiopathogenesis-incidence-and-diagnosis-of-opioid-induced-constipation

\section{INTECH}

open science | open minds

\section{InTech Europe}

University Campus STeP Ri

Slavka Krautzeka 83/A

51000 Rijeka, Croatia

Phone: +385 (51) 770447

Fax: +385 (51) 686166

www.intechopen.com

\section{InTech China}

Unit 405, Office Block, Hotel Equatorial Shanghai

No.65, Yan An Road (West), Shanghai, 200040, China

中国上海市延安西路65号上海国际贵都大饭店办公楼 405 单元

Phone: +86-21-62489820

Fax: +86-21-62489821 
(C) 2012 The Author(s). Licensee IntechOpen. This is an open access article distributed under the terms of the Creative Commons Attribution 3.0 License, which permits unrestricted use, distribution, and reproduction in any medium, provided the original work is properly cited. 